\title{
Body mass index and gestational weight gain in two selected Medical Officer of Health areas in the Gampaha District \\ C Abeysena ${ }^{1}$, P Jayawardana ${ }^{2}$
}

\begin{abstract}
Objective:

To describe gestational weight gain pattern according to the body mass index (BMI) categories.
\end{abstract}

Methods:

This is a descriptive study conducted in two Medical Officer of Health areas of the Gampaha District. Pregnant women were recruited on or before 16 weeks of gestation and followed up until delivery. Maternal weight was measured at the booking visit, during the second trimester and at delivery. Inadequate and excessive weight gain were defined as weight gain below and above the Institute of Medicine (IOM) 2009 recommendations for the BMI categories as well as Ministry of Health $(\mathrm{MoH})$ recommendations.

Results:

Two hundred and forty seven (30\%) of the women were underweight, $432(52 \%)$ were normal weight and $131(18 \%)$ overweight and obese. According to the Asian BMI classification, 338(41 \%) were normal weight and 225(29\%) were overweight and obese. Total mean weight gain for the sample was 10.6(SD 3.3) $\mathrm{kg}$ and mean rate of gestational weight gain was 0.27 (SD 0.08) $\mathrm{kg} /$ week. Mean weight gain during second trimester was $6.7(\mathrm{SD} 2.7) \mathrm{kg}$ and during third trimester 3.9(SD 2.2) kg. Mean gestational weight gain and rate of weight gain per week was higher among underweight women. Of the $710,404(57 \%)$ women gained less and $62(8.7 \%)$ more weight, than recommended by the IOM, whereas $108(15 \%)$ gained more weight by $\mathrm{MoH}$ standards.

\section{Conclusions:}

One third of the women were underweight and mean gestational weight gain and rate of weight gain per week were higher amongst them. More than half of the women gained less weight than recommended.

Key Words - Body mass index, gestation, pregnancy, weight gain

\section{Introduction}

Gestational weight gain is crucial for both maternal and fetal pregnancy outcomes. Inadequate weight gain during pregnancy is a major maternal health problem in developing countries. Several authors ${ }^{1-10}$ had reported inadequate weight gain to be associated with preterm birth, birth weight, low birth weight, small for gestational age and failure to initiate breastfeeding. Excessive weight gain during pregnancy is a public health problem in developed countries. Three studies have reported that the weight gain exceeded more than the recommended range for over $50 \%$ of mothers. ${ }^{11-13}$ Excessive gestational weight gain too results in both maternal and fetal adverse pregnancy outcomes and delivery complications. Children of mothers who gained more than the recommended weight gain had a greater risk of being overweight at seven years of age ${ }^{14,15}$ than for children of mothers who met the weight gain recommendations. Being an overweight child was associated with higher systolic blood pressure in later life. ${ }^{14}$

The effects of gestational weight gain on pregnancy outcome depend on the woman's pre-pregnancy body mass index (BMI). ${ }^{16}$ The Institute of Medicine (IOM) released new guidelines ${ }^{17}$ for gestational weight gain in
2009 which is shown in Table 1. According to these, optimal levels for gestational weight gain were based on the maternal BMI status. Pregnancy weight gain within the IOM recommendations were observed to be associated with better outcomes. ${ }^{18}$ The data on gestational weight gain pattern are not available in Sri Lanka. Therefore the objective of this study was to describe gestational weight gain pattern according to the BMI categories.

\section{Methods}

This is a descriptive component of a cohort study which was carried out in two Medical Officer of Health (MOH) areas namely Ja-ela and Ragama in the Gampaha District which cover both urban and rural areas. Both these $\mathrm{MOH}$ areas conduct 36 antenatal clinics per month. The study was conducted between May 2001 to April 2002. All pregnant mothers eligible to participate in the study were recruited from the antenatal clinics on or before 16 weeks of gestation and followed up until delivery. Exclusion criteria were age $<15$ years, pre-existing diabetes mellitus and hypertension and multiple pregnancies. Details of this study have been published elsewhere. ${ }^{19}$

1. Senior Lecturer / Department of Public Health, Faculty of Medicine, University of Kelaniya, Ragama

2. Professor in Community Medicine / Department of Public Health, Faculty of Medicine, University of Kelaniya, Ragama 
Maternal weight was measured at the booking visit, during the second trimester and at delivery. The technique of measurement was standardized and the weighing machines in the clinics were calibrated regularly using a known weight. BMI was determined based on the weight and height measurements of the first antenatal clinic visit. Inadequate and excessive weight gain based on the BMI categories were defined separately according to both the IOM and the Ministry of Health standards. $^{20}$

Data were analysed for the total sample and women with normal pregnancy outcome separately. Normal pregnancy outcome was defined as those pregnancies which were not associated with maternal complications during pregnancy in terms of ante partum haemorrhage, pregnancy induced hypertension, eclampsia and gestational diabetes mellitus and those which did not end up in fetal death, preterm delivery and caesarean deliveries.

\section{Results}

The total number recruited to the study was 885 . Fifty six mothers were excluded from the analysis due to multiple pregnancies (10) and fetal deaths (46). Of the remaining 829 mothers, 247 (30\%) had a BMI of $<18.5$ $\mathrm{kg} / \mathrm{m}^{2}, 432$ (52\%) between 18.5-24.9 kg/m², $114(14 \%)$ between $25.0-29.9 \mathrm{~kg} / \mathrm{m}^{2}$ and $17(2 \%) \geq 30 \mathrm{~kg} / \mathrm{m}^{2}$. For $19(2.3 \%)$, the BMI values were missing. The corresponding values according to Asian BMI categories were $247(30 \%)$ for $<18.5 \mathrm{~kg} / \mathrm{m}^{2}, 338$ (41\%) between $18.5-22.9 \mathrm{~kg} / \mathrm{m}^{2}, 179(21.6 \%)$ between $23.0-27.4 \mathrm{~kg} /$ $\mathrm{m}^{2}$ and $46(5.5 \%) \geq 27.5 \mathrm{~kg} / \mathrm{m}^{2}$.

For the assessment of weight gain, 119 (14.4\%) mothers had to be excluded from the analysis due to non availability of weight measurements at the first antenatal visit or at the last assessment. Therefore the final sample included in the analysis of weight gain was 710 .

Total mean weight gain for the sample was 10.6 (SD $3.3) \mathrm{kg}$ and mean rate of gestational weight gain was 0.27 (SD 0.08) kg/week. Mean weight gain during second trimester was 6.7 (SD 2.7) $\mathrm{kg}$ and during third trimester 3.9 (SD 2.2) kg.

Of the 710, $404(57 \%)$ mothers gained less and 62 $(8.7 \%)$ gained more weight, than that recommended by the IOM 2009 guidelines (Table 2). However, according to the Ministry of Health weight gain classification $15 \%$ (108) had excessive weight gain. It was also observed that $67 \%(n=140)$ of underweight and $61 \%$ $(n=237)$ of normal weight women, had inadequate weight gain according to the both classifications. Five percent $(n=19)$ of normal weight and $29 \%(n=29)$ of overweight women has had excessive weight gain according to the IMO standards, which was $11 \%(n=44)$ and $43 \%(n=43)$ according to the Ministry of Health standards respectively.
The highest rate of weight gain per week was observed among underweight women which showed a gradual decrease through normal weight to overweight category (Table 2). A similar trend was observed among mothers who underwent a normal pregnancy (Table 3) and when the BMI status was categorized according to Asian standards (Table 4).

Table 1 - Institute of Medicine (IOM) of the National Academies and Ministry of Health (MoH) recommendations for total weight gain during pregnancy, by pre pregnancy BMI

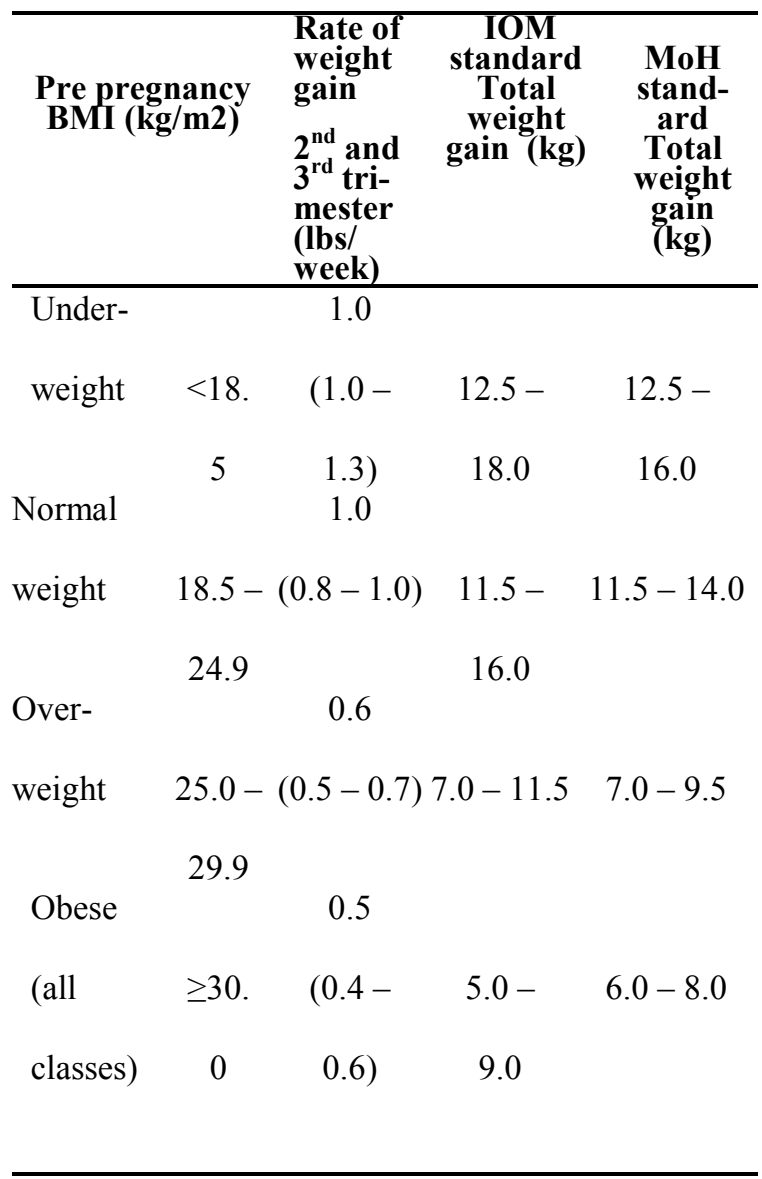

Source: Adopted from the Institute of Medicine of the National Academies and WHO 
Table 2 - Gestational weight gain pattern in the total sample IOM and Ministry of Health (MoH) standard, by pre pregnancy BMI

\begin{tabular}{|c|c|c|c|c|c|c|c|c|}
\hline \multirow{2}{*}{$\begin{array}{l}\text { Pre pregnancy } \\
\text { BMI }\left(\mathrm{kg} / \mathrm{m}^{2}\right)\end{array}$} & \multicolumn{3}{|c|}{ IOM standard } & \multicolumn{3}{|c|}{ MoH standard } & \multirow{2}{*}{$\begin{array}{l}\text { Weight } \\
\text { gain }(\mathbf{k g})\end{array}$} & \multirow{2}{*}{$\begin{array}{c}\text { Weight } \\
\text { gain per } \\
\text { week (kg) }\end{array}$} \\
\hline & $\begin{array}{c}\text { Inade- } \\
\text { quate } \\
\text { weight } \\
\text { gain } \\
\text { n }\end{array}$ & $\begin{array}{c}\text { Normal } \\
\text { weight } \\
\text { gain } \\
\text { n }\end{array}$ & $\begin{array}{c}\text { Excess } \\
\text { weight } \\
\text { gain }\end{array}$ & $\begin{array}{c}\text { Inade- } \\
\text { quate } \\
\text { weight } \\
\text { gain } \\
\text { n }\end{array}$ & $\begin{array}{c}\text { Normal } \\
\text { weight } \\
\text { gain } \\
\text { n }\end{array}$ & $\begin{array}{c}\text { Excess } \\
\text { weight } \\
\text { gain }\end{array}$ & & \\
\hline $\begin{array}{l}\text { Underweight } \\
<18.5(\mathrm{n}=210)\end{array}$ & $\begin{array}{c}140 \\
(67 \%)\end{array}$ & $66(31 \%)$ & $4(2 \%)$ & $\begin{array}{c}140 \\
(67 \%)\end{array}$ & $59(28 \%)$ & $11(5 \%)$ & $11.2(3.2)$ & $\begin{array}{c}0.28 \\
(0.08)\end{array}$ \\
\hline $\begin{array}{l}\text { Normal weight } \\
18.5-24.9 \\
(n=386)\end{array}$ & $\begin{array}{c}237 \\
(61 \%)\end{array}$ & $\begin{array}{c}130 \\
(34 \%)\end{array}$ & $19(5 \%)$ & $\begin{array}{c}237 \\
(61 \%)\end{array}$ & $\begin{array}{c}105 \\
(27 \%)\end{array}$ & $\begin{array}{c}44 \\
(11 \%)\end{array}$ & $10.6(3.2)$ & $\begin{array}{c}0.27 \\
(0.08)\end{array}$ \\
\hline $\begin{array}{l}\text { Overweight } \\
25.0-29.9 \\
(n=101)\end{array}$ & $\begin{array}{c}26 \\
(25.7 \%)\end{array}$ & $\begin{array}{c}46 \\
(45.5 \%)\end{array}$ & $\begin{array}{c}29 \\
(28.7 \%)\end{array}$ & $\begin{array}{c}26 \\
(25.7 \%)\end{array}$ & $\begin{array}{c}32 \\
(31.7 \%)\end{array}$ & $\begin{array}{c}43 \\
(42.6 \%)\end{array}$ & $9.2(3.4)$ & $\begin{array}{c}0.23 \\
(0.08)\end{array}$ \\
\hline $\begin{array}{l}\text { Obese } \\
\geq 30.0(n=13)\end{array}$ & $1(7.7 \%)$ & $\begin{array}{c}2 \\
(15.4 \%)\end{array}$ & $\begin{array}{c}10 \\
(77 \%)\end{array}$ & $2(15 \%)$ & $1(7.7 \%)$ & $\begin{array}{c}10 \\
(77 \%)\end{array}$ & $10.8(3.1)$ & $\begin{array}{c}0.27 \\
(0.08) \\
\end{array}$ \\
\hline
\end{tabular}

IOM - Institute of Medicine

Table 3 - Weight gain pattern in normal pregnancies, by pre pregnancy BMI

\begin{tabular}{lccc}
\hline $\begin{array}{l}\text { Pre pregnancy } \\
\text { BMI }\left(\mathbf{k g} / \mathbf{m}^{\mathbf{2}}\right)\end{array}$ & $\begin{array}{c}\text { Weight } \\
\text { gain } \\
\text { (kg) } \\
\text { Mean } \\
\text { (SD) }\end{array}$ & $\begin{array}{c}\text { 95\% refer- } \\
\text { ence range } \\
\text { (kg) }\end{array}$ & $\begin{array}{c}\text { Weight } \\
\text { gain } \\
\text { (kg per } \\
\text { week) } \\
\text { Mean } \\
\text { (SD) }\end{array}$ \\
\hline Underweight $<$ & & & \\
18.5 & 11.4 & $5.28-17.50$ & 0.29 \\
$\mathrm{n}=169$ & $(3.1)$ & & $(0.08)$ \\
Normal weight & & & \\
$18.5-24.9$ & 10.5 & $4.14-16.9$ & 0.27 \\
$\mathrm{n}=255$ & $(3.3)$ & & $(0.08)$ \\
$\begin{array}{l}\text { Overweight } \\
25.0-29.9\end{array}$ & 9.0 & $2.75-15.25$ & 0.23 \\
$\mathrm{n}=59$ & $(3.2)$ & & $(0.08)$ \\
Obese $\geq 30.0$ & & & \\
$\mathrm{n}=5$ & 12.0 & & 0.29 \\
& $(0.7)$ & & $(0.02)$ \\
\hline
\end{tabular}

Table 4 - Gestational weight gain pattern in the total sample, by Asians pre-pregnancy BMI

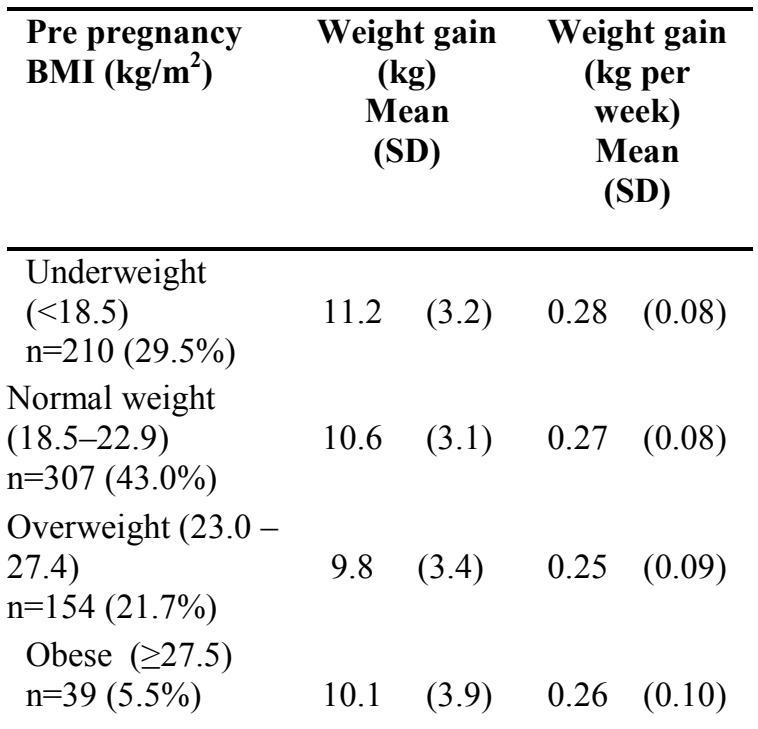




\section{Discussion}

According to the BMI classification, this study indicates that $30 \%$ of the pregnant women were underweight and $54 \%$ of them were normal weight and $16 \%$ overweight and obese. According to Asian BMI classification $41 \%$ were normal weight and $29 \%$ were overweight and obese.

A review article reported that the BMI cut-off points for overweight and obesity of Asian populations are lower than the international BMI cut-off points recommended by the WHO. ${ }^{21}$ Because Asian populations were noted to have higher cardiovascular risk factors than Western populations at any BMI level. ${ }^{21}$ Wen et al had reported that among the Asian population, significant mortality risks started at BMI $\geq 25.0 \mathrm{~kg} / \mathrm{m}^{2}$, rather than at BMI $\geq 30.0 \mathrm{~kg} / \mathrm{m}^{2}{ }^{22}$ The study supported the use of BMI $\geq 25.0 \mathrm{~kg} / \mathrm{m}^{2}$ as a new cut-off point for obesity and BMI of $23.0-24.9 \mathrm{~kg} / \mathrm{m}^{2}$ for overweight. ${ }^{22}$ Another study had reported that using revised cut points would greatly increase the estimated burden of obesity-related metabolic disorders among South Asians, Chinese and Aboriginals. ${ }^{21}$ Therefore, necessity to develop and redefine appropriate BMI cut-off points which are countryspecific and ethnic-specific for Asians has also been suggested by some. ${ }^{23}$

We found that $57 \%$ women gained less and $8.7 \%$ more weight, than recommended by the IOM 2009 guidelines. According to the WHO standard excessive weight gain was $15 \%$. Excessive gestational weight gain is more prevalent than inadequate weight gain in developed countries. One study reported that $30.6 \%$ of women gained the recommended amount of weight during pregnancy where as $52.3 \%$ gained more weight , and $17.1 \%$ less than recommended according to the IOM 1990 guidelines. ${ }^{11}$ Olson had reported that only about $33 \%$ to $40 \%$ of U.S. women gain within IOM recommendations. ${ }^{18}$ Another study reported that one third of women gained within the recommended range, $22 \%$ gained below, and $45 \%$ gained above the range. ${ }^{13}$

The optimal weight gain in women of BMI $<18.5 \mathrm{~kg} /$ $\mathrm{m}^{2}, 18.5-25 \mathrm{~kg} / \mathrm{m}^{2}$ and $25-29 \mathrm{~kg} / \mathrm{m}^{2}$ in the present study were 5-17 kg; 4-17 kg and 3-15 kg respectively. One study from Sweden reported that the optimal gestational weight gain in women by pre-pregnancy BMI was $4-10 \mathrm{~kg}$ for BMI $<20 \mathrm{~kg} / \mathrm{m}^{2} ; 2-10 \mathrm{~kg}$ for BMI 20$24.9 \mathrm{~kg} / \mathrm{m}^{2} ;<9 \mathrm{~kg}$ for BMI $25-29.9 \mathrm{~kg} / \mathrm{m}^{2}$; and $<6 \mathrm{~kg}$ for BMI of $30 \mathrm{~kg} / \mathrm{m}^{2}$ or more. ${ }^{24}$

We found that the mean weight gain as well as rate of mean weight gain per week were higher among underweight and normal weight women respectively than overweight women. Our findings were consistent with the results reported by several authors. ${ }^{6,17,25}$

Our study has several limitations. We recruited pregnant women on average at 12 weeks of gestation and the weight measurements were made at that point. Ideally it would be better to take pre-pregnancy weight instead of booking visit for determining gestational weight gain. The sample size was not adequate for determining mean gestational weight gain, 95\% reference range for weight gain among normal pregnancies and the proportion of inadequate and excessive weight gain for obese women. As the study was confined to two $\mathrm{MOH}$ areas in the Gampaha District, generalizability of the results are to be done cautiously.

\section{References}

1. Rode L, Hegaard HK, Kjaergaard H, Møller LF, Tabor A, Ottesen B. Association between maternal weight gain and birth weight. Obstet Gynecol. 2007;109(6):1309-15.

2. Viswanathan M, Siega-Riz AM, Moos MK, Deierlein A, Mumford S, Knaack J, Thieda P, Lux LJ, Lohr KN. Outcomes of maternal weight gain. Evid Rep Technol Assess (Full Rep). 2008;(168):1-223.

3. DeVader SR, Neeley HL, Myles TD, Leet TL. Evaluation of gestational weight gain guidelines for women with normal prepregnancy body mass index. Obstet Gynecol. 2007;110 (4):745-51.

4. Frederick IO, Williams MA, Sales AE, Martin DP, Killien M. Pre-pregnancy body mass index, gestational weight gain, and other maternal characteristics in relation to infant birth weight. Matern Child Health J. 2008;12(5):557 $-67$.

5. Helms E, Coulson CC, Galvin SL. Trends in weight gain during pregnancy: A population study across 16 years in North Carolina. American Journal of Obstetrics and Gynecology. 2006;194:e32-e34.

6. Siega-Ris AM, Adair LS, Hobel CJ. Maternal underweight status and inadequate rate of weight gain during the third trimester of pregnancy increases the risk of preterm delivery. The Journal of Nutrition. 1996;126:146-153.

7. Ehrenberg HM, Dierker L, Milluzzi C, Mereer BM. Low pregnancy weight, failure to thrive in pregnancy, and adverse pregnancy outcome. American Journal of Obstetrics and Gynecology. 2003;189:1726-30.

8. Nielsen JN, O'Brien KO, Witter FR, Chang SC,Mancini J, Nathanson MS, Caulfield LE. High gestational weight gain dose not improve birth weight in a cohort of African adolescents. American Journal of Clinical Nutrition. 2009;84:183-9.

9. Marsoosi V, Jamal A, Eslamian L. Prepregnancy weight, low pregnancy weight gain, and preterm delivery. International Journal of Gynecology and Obstetrics. 2004;87;36-37.

10. Carmichael S, Abrams B, Selvin S. The association of pattern of maternal weight gain with length of gestation and risk of spontaneous preterm delivery. Paediatric and Perinatal Epi- 
demiology. 1997;11:392-406.

11. Crane JM, White J, Murphy P, Burrage L, Hutchens D. The effect of gestational weight gain by body mass index on maternal and neonatal outcomes. J Obstet Gynaecol Can. 2009;31(1):28-35.

12. Brawarsky P, Stotland NE, Rackson RA, et al. Prepregnancy and pregnancy related factors and the risk of excessive or inadequate gestational weight gain. International Journal of Gynecology and Obstetrics. 2005;91:125-131.

13. Chasan-Taber L, Schmidt MD, Pekow P, Sternfeld B, Solomon CG, Markenson G. Predictors of excessive and inadequate gestational weight gain in Hispanic women. Obesity. 2008;16:1657-66.

14. Wrotniak BH, Shults J, Butts S, Stettler N. Gestational weight gain and risk of overweight in the offspring at age $7 \mathrm{y}$ in a multicenter, multiethnic cohort study. Am J Clin Nutr. 2008 Jun;87(6):1818 -24 .

15 Mamun AA, O'Callaghan M, Callaway L, Williams G, Najman J, Lawlor DA. Associations of gestational weight gain with offspring body mass index and blood pressure at 21 years of age: evidence from a birth cohort study. Circulation. 2009 7;119 (13): 1720-7.

16. Crane JM, White J, Murphy P, Burrage L, Hutchens $\mathrm{D}$. The effect of gestational weight gain by body mass index on maternal and neonatal outcomes. J Obstet Gynaecol Can. 2009;31(1):28-35.

17. Institute of Medicine. Weight gain During Pregnancy: Reexamining the Guidelines, Washington, DC: The National Academies press. Posted online May 2009.

18. Olson CM. Achieving a healthy weight gain during pregnancy. Annu Rev Nutr. 2008;28:411-23.

19. Abeysena C, Jayawardana P, Seneviratne R De A. Effect of energy expenditure on pregnancy outcome: A cohort study. Journal of College of Community Physicians of Sri Lanka 2008; 13 (2): 1-8.

20. Ministry of Health. Integrated nutritional package. Key interventions to improve maternal and child nutrition in Sri Lanka.

21. Low S, Chin MC, Ma S, Heng D, Deurenberg-Yap M. Rationale for redefining obesity in Asians. Ann Acad Med Singapore. 2009;38(1):66-9.

22. Wen CP, David Cheng TY, Tsai SP, Chan HT, Hsu HL, Hsu CC, Eriksen MP. Are Asians at greater mortality risks for being overweight than Caucasians? Redefining obesity for Asians. Public Health Nutr. 2009;12(4):497-506

23. Razak F, Anand SS, Shannon H, Vuksan V, Davis B, Jacobs R, Teo KK, McQueen M, Yusuf S. Defining obesity cut points in a multiethnic population. Circulation. 2007 Apr 24;115(16):2111-8.

24. Cedergren MI. Optimal gestational weight gain for body mass index categories. Obstet Gynecol. 2007;110(4):759-64.

25. Maddah M. Pregnancy weight gain in Iranian women attending a cross-sectional study of public health centres in Rasht. Midwifery. 2005;21:365-370. 